\title{
HET ACCOUNTANTSBEROEP IN SPANJE ${ }^{1}$ )
}

door Drs. Jac. Krikke

De volgende punten zullen worden besproken:

I. De organisatie van het beroep;

II. De opleiding voor het beroep en de toelating tot het Instituut;

III. De wet op de rechtsvorm van de naamloze vennootschappen;

IV. De functie van de accountant.

\section{De organisatie van bet beroep}

De toonaangevende vereniging van accountants in Spanje is het „Instituto de Censores Jurados de Cuentas de España". Dit Instituut heeft de volgende voorlopers gehad:

1 Het „Instituto de Contadores Publicos de España”, een vereniging van administratieve deskundigen in vrij beroep, opgericht in 1912. Deze vereniging ging teniet als gevolg van gebrek aan belangstelling van de beroepsgenoten.

2 Het „Colegio de Contadores Jurados de Bilbao". Dit „Colegio”, opgericht in 1927, wist zich te handhaven tot het opging in het "Instituto de Censores Jurados de Cuentas". Als toelatingseisen voor het "Colegio" golden onder meer dat men een officieel erkende titel moest hebben van een handelsschool en een stage van vier jaar met goed gevolg doorlopen moest hebben.

3 Het ,Colegio de Contadores de Madrid”, opgericht in 1936.

4 Het „Colegio de Contadores Jurados de Cataluña”, eveneens opgericht in 1936.

5 Het „Colegio de Contadores Jurados de Vigo”, met eveneens 1936 als oprichtingsjaar.

Het "Colegio" van Cataluña, dat in Barcelona was gevestigd, had een kortstondig bestaan. Ook de overigen kwamen niet van de grond, als gevolg van

- de te smalle regionale basis;

- de ,gesloten-gilde-zucht" (beperking van het aantal leden);

- de burgeroorlog.

De regionale geest werd in de hand gewerkt doordat Spanje uit verschillende volkeren bestaat met eigen zeden en gewoonten.

De genoemde „colegios” omvatten respectievelijk Basken, Castiljanen, Catalanen en Galliciers. De burgeroorlog met al de ellende daaraan verbonden en de internationale boycot tegen Spanje versterkten echter het nationale saamhorigheidsgevoel en maakten - in 1942 - de totstandkoming mogelijk van het „Consejo Superior de Colegios Oficales de Titulares Mercantiles". Dit „Consejo”, met nationaal karakter, omvat alle „titulares mercantiles” (bezitters van het diploma van een handelsschool). Met de oprichting van het "Consejo Superior" was de weg geopend voor een nationaal instituut van accountants, dat onder de naam van

1) De heer F. W. H. B. van Schoonhoven, chef Accountantsdienst Philips voor Spanje en Portugal, die zo bereidwillig was waardevolle inlichtingen over de ontwikkeling van het beroep in Spanje te verschaffen, ben ik daarvoor zeer erkentelijk. $K r$.

m a b blz. 288 
„Instituto de Censores Jurados de Cuentas de España”, op 16 april 1945 zijn beslag kreeg.

Het ,Instituto" bedoelt te zijn een selectie van in het bijzonder op accountantsgebied deskundige „titulares mercantiles”.

De ,censor” (men lette op de ontwikkeling van ,contador” = boekhoudkundige naar ,censor" = controleur) is verplicht deel uit te maken van een regionale vereniging van "titulares mercantiles”. De ,censores" vallen daarom organisatorisch allen onder de „Consejo Superior de Colegios de Titulares Mercantiles”. Onder de "Consejo Superior" ressorteren derhalve zowel de 34 regionale verenigingen van ,titulares mercantiles” als het Instituut van de „censores”. De taak van de "Consejo Superior" bestaat onder meer in het peilen van de opvattingen in de onder haar staande organisaties, in het verrichten van alle handelingen op haar gebied voorzover zij een nationaal karakter hebben, in het bij de overheid aanhangig maken van wensen die in het beroep leven, in het uitgeven van het orgaan „Tecnica Economica”, in het beleggen van allerlei vergaderingen en conferenties, in het organiseren van cursussen voor "titulares mercantiles" enz.

Alle „titulares mercantiles" die het beroep willen uitoefenen, moeten bij hun provinciaal ,colegio" worden ingeschreven. De leden van een zodanig "colegio" zijn in twee categorieën verdeeld: "titulares mercantiles” die het beroep uitoefenen en zij die dit niet doen. Onder , uitoefening van het beroep" wordt verstaan het in vrij beroep werkzaam zijn en niet het als accountant werkzaam zijn in dienstbetrekking (hetzij bij het bedrijfsleven, hetzij bij de overheid).

De provinciale verenigingen zijn met het toezicht op de leden in hun provincie belast. $\mathrm{Zij}$ leveren ook een aantal leden voor het bestuur van de "Consejo Superior".

De indruk bestaat dat de verhouding tussen de "Consejo Superior” en het „Instituto" in directe, organisatorische lijn, heel los is. Aangezien echter de leden van het "Instituto" voortkomen uit de "titulares mercantiles", bestaat via de leden zèlf wel een sterke band tussen „Instituto" en "Consejo Superior".

Gezien de betekenis van de functie van de "censor" zal verder in hoofdzaak hierover gehandeld worden.

Het Instituut van de „,censores” is een officieel erkende vereniging met volledige rechtspersoonlijkheid. Het kent

- ereleden (die al dan niet accountant zijn);

- leden in vrij beroep;

- Ieden, die niet het beroep uitoefenen;

- adjunct-leden.

Tot voor kort was de situatie zo dat ingevolge de statuten het totaal aantal leden in vrij beroep niet groter mocht zijn dan 350 . Door een in 1962 van kracht geworden statutenwijziging is thans het aantal leden-in-vrij-beroep onbeperkt (artikel 14 nieuwe statuten). Het aantal adjunct-leden zal bepaald worden door het bestuur; bij de vaststelling van dit aantal zullen ,,de behoeften van het Instituut" het richtsnoer zijn. Met de laatste categorie weet men niet al te best raad. Practisch is het zo dat het aantal adjunct-leden zeer klein is. Men wil hen zo spoedig mogelijk tot gewoon lid maken; het vraagstuk van de adjunct-leden zal daarmee van de baan zijn. 


\section{De opleiding voor bet beroep en de toelating tot het "Instituto" \\ Wat de opleiding betreft, zijn er verschillende mogelijkheden.}

\section{De „Escuelas técnicas de Comercio" ("Technische handelsschool”)}

Hier wordt economisch-commercieel gericht onderwijs gegeven. Er wordt opgeleid tot „perito mercantil". De minimum-leeftijd is 14 jaar en de opleiding duurt 3 jaar.

$\mathrm{Na}$ de titel „perito mercantil” kan men - na nogmaals drie jaar - de titel „profesor mercantil" behalen. Deze titel (niet te vereenzelvigen met „professor”!) is vereist om als lid van het Instituut der „censores jurados" te worden geaccepteerd.

Het bezit van deze beide titels geeft eveneens recht op toegang tot de universitaire studie in de economische- en handelswetenschappen; de laatste titel waarborgt daarvoor de verstgevorderde vooropleiding, ook als men haar vergelijkt met andere vooropleidingen. Als men op 14-jarige leeftijd begonnen is op de handelsschool en als 20-jarige ,profesor mercantil” is, kan men na minimaal 3 jaar het doctoraal examen aan de universiteit afleggen.

Jaren geleden werd op de handelsscholen ook nog verder opgeleid en wel tot ,intendente mercantil” en tot ,actuario de seguros" (verzekeringswiskundige). Deze verdere opleiding werd evenwel onvoldoende geacht en is daarom stopgezet en naar de universiteiten verwezen.

Het onderwijs aan de handelsscholen omvat onder meer comptabiliteit, economie, belastingsrecht en verwante vakken; het is meer gespecialiseerd dan het onderwijs aan de meer algemene

\section{Institutos de Enseñanza}

Er zijn twee soorten van deze onderwijsinstellingen die thans van belang zijn, namelijk de „Enseñanza Media” en de „Enseñanza Laboral”, die ongeveer vergeleken kunnen worden met onze H.B.S.

De opleiding aan de eerstgenoemde scholen - waar men op 10-jarige leeftijd naar toe kan - duurt zes jaren. Hierna is men "bachiller superior" en kan zich - desgewenst - voorbereiden voor het examen voor „perito mercantil” der handelsscholen (daarna eventueel voor "profesor mercantil”"). Na de 6 jaar is er nog één jaar een „pre-universitaire” opleiding voor hen die rechtstreeks naar de universiteit willen.

De opleiding van de „Enseñanza Laboral” - waar men eveneens op 10-jarige leeftijd naar toe kan - duurt in totaal 7 jaar en wordt afgesloten met het examen voor „,bachillerato laboral administrativo superior”. Dit examen staat dicht bij het examen voor "perito mercantil" van de handelsscholen en geeft eveneens toegang tot de universiteit. Het onderwijs aan deze „Enseñanza Laboral” staat qua karakter dichter bij het onderwijs aan de handelsscholen dan dat van de gewone middelbare scholen, de „Enseñanza Media”.

\section{Universitaire opleiding}

Zoals reeds uit het voorgaande bleek, zijn er drie diploma's waarmee men deze kan volgen:

- „perito mercantil” en ,profesor mercantil” van de handelsscholen (bij de 
laatste kan men, als gezegd, na minimaal 3 jaar de academische studie voltooien;

- einddiploma van de beide soorten ,,institutos”.

Wat de toegang tot de universiteit betreft, staan zij alle - uitgezonderd het hogere diploma ,profesor mercantil” - min of meer op vergelijkbaar niveau.

De academische opleiding duurt 5 jaar, waarvan de eerste 4 jaar voor allen gelijk is. Na 4 jaar was men „licentiaat” (,,intendente”). In het vijfde jaar kan men zich specialiseren in algemene economie, bedrijfseconomie of actuariaat en hierin het doctoraal examen doen. Men is dan „doctorado". Het is de bedoeling dat in de toekomst de universitaire opleiding alleen de titel „doctorado" zal kennen.

Om tot het Instituut van de "censores" te worden toegelaten en daarmee als „,censor" in vrij beroep te kunnen optreden, moet men onder meer aan de volgende eisen voldoen:

a de Spaanse nationaliteit bezitten;

b van het mannelijk geslacht zijn;

c in het bezit zijn van de titel „,profesor mercantil" (tenzij men adjunct-lid wil worden);

$\mathrm{d}$ ingeschreven zijn in het register van het "Colegio Oficial de Titulares Mercantiles" van zijn provincie;

e beschikken over een "licencia fiscal" (d.i. het bij de fiscus geregistreerd zijn als, ,in vrij beroep werkzaam").

Verdere titels dan ,profesor mercantil” - zoals „intendente mercantil” en „actuario" worden op prijs gesteld, maar zijn niet vereist.

De gang van zaken is volgens het Interne Reglement (art. 66) zo dat men, om lid te worden, eerst ,,censor jurado adjunto" moet worden ${ }^{2}$ ) en een stage van drie jaar moet doorlopen bij een "censor" die het beroep uitoefent (een "censor numerario"). Aan het eind van de drie jaar moet de candidaat een "these" opstellen en verdedigen voor de vaktechnische commissie van het Instituut.

Van het doorlopen van een stage komt echter in de praktijk nog weinig terecht. Genoemd artikel eist ook dat het adjunct-lid drie jaar zijn beroepsbelasting moet hebben betaald. Het betalen van deze belasting geldt als criterium dat hij het beroep in feite die jaren uitoefent.

"Profesor mercantil" - de basiseis voor het lidmaatschap - is naar Spaanse begrippen een titel, omdat zij verkregen is op grond en ter afsluiting van studie. De benaming ,censor jurado de cuentas” is geen echte titel in de Spaanse zin van het woord, doch een aanduiding dat men lid is van het Instituut der „censores jurados". Niettemin is de laatste kwalificatie wel wettelijk beschermd. Men zou haar in Nederland een beschermde beroepsaanduiding kunnen noemen.

Eerst moet thans - tot beter begrip van de functie van de „censor jurado" gehandeld worden over:

3) Inzake de voorwaarden voor toelating als adjunct-lid werden in de reglementen geen positieve aanwijzingen gevonden; slechts wordt gezegd dat deze voorwaarden door de algemene vergadering zullen worden vastgesteld. 


\section{De Wet op de rechtsvorm der naamloze vennootschappen (1951)}

In 1885 is in Spanje in werking getreden een wetboek van koophandel welks bepalingen gelden voor allen die handel drijven. Deze wet verplicht de ondernemingen onder meer jaarlijks een verslag en een balans op te stellen. De naamloze vennootschappen moeten dit ook, maar zij hebben bovendien de plicht balansen te publiceren. Verslag en balans moeten ,met exactheid de verschillende categorieën bezittingen en schulden aangeven".

De wet van 17 juli 1951 heeft de voorschriften m.b.t. naamloze vennootschappen verscherpt. $Z$ ij bepaalt dat de balans, de verlies- en winstrekening en de toelichting gezamenlijk niet alleen een exact en betrouwbaar overzicht moeten zijn van de vermogenstoestand der n.v. en van de behaalde resultaten, maar dat het gehele jaarverslag een getrouw beeld moet geven van de ,economische positie" van de vennootschap en van de financiële en economische ontwikkeling van zijn zaken.

Met betrekking tot de balans wordt dit nader uitgewerkt in de artikelen 102 en 105 waarin t.a.v. de opbouw van de balans wordt voorgeschreven dat deze aan de debetzijde tenminste een 15-tal posten moet laten zien en aan de creditzijde een 7-tal (met name genoemd).

Er bestaan ook voorschriften voor de waardering van de voornaamste activa en passiva (artikel 104). Deze waarderingsvoorschriften gelden ook voor andere ondernemingsvormen dan n.v.'s.

Artikel 105 geeft enkele bepalingen voor de verlies- en winstrekening. Ook hier streeft de wetgever een duidelijk inzicht na.

Een permanent toezichthoudend orgaan, zoals in Nederland de raad van commissarissen, kennen de Spaanse n.v.'s niet. Het toezicht wordt geregeld in artikel 108 waarvan lid 2 bepaalt dat de jaarstukken ter controle moeten worden voorgelegd aan een tweetal „controleurs" die door de algemene vergadering moeten worden gekozen uit de aandeelhouders. Kan de algemene vergadering het niet unaniem eens worden over de keuze van deze controlerende aandeelhouders - die geen deel mogen uitmaken van het bestuur van de onderneming - dan heeft een minderheid, wanneer zij tenminste $1 / 10$ van het gestorte kapitaal vertegenwoordigt, het recht een andere „censor" (plus plaatsvervangende „censor”) te kiezen, maar die moeten dan afkomstig zijn uit de leden van het Instituut der ,"censores".

Dit is echter niet de enige wijze waarop de ,censores” bij de controle van n.v.'s kunnen worden betrokken. Artikel $108 \mathrm{zegt} \mathrm{nl}$. dat de aandeelhouders-controleurs hun controletaak zelf kunnen uitoefenen (elk afzonderlijk of gezamenlijk), maar zich ook kunnen doen bijstaan door ,personas tecnicas".

De taak en de bevoegdheden van de controleurs zijn in artikel 108 omschreven. In de praktijk is de controle van de aandeelhouders-controleurs beperkt tot het nagaan van de vraag of de jaarrekening ,getrouw aan de boekhouding is ontleend". De taak van de beroepscontroleurs gaat wel verder; zij moeten de juistheid en waarheid van de jaarrekening vaststellen en de waarderingen van de verschillende posten (waaronder ook de afschrijvingen) controleren. Bij hun controle mogen zij de boekhouding en alle onderliggende documenten onderzoeken, maar hun rapport zal alleen betrekking dienen te hebben op de juistheid en betrouwbaarheid van de gegevens in de jaarrekening. Hun controle is in zijn betekenis 
echter in feite nog te beperkt ${ }^{3}$ ). Het bestuursbeleid als zodanig mag ingevolge artikel 108 niet in de beoordeling betrokken worden. Het feit dat de controle door de aandeelhouders-controleurs al dan niet tezamen met de controle door een minderheidsberoepsaccountant een uitvloeisel is van het wetsvoorschrift, vindt o.m. uitdrukking in verschillende Spaanse accountantsrapporten. In een model, voorkomend in „Die Prüfung des Jahresabschlusses” (Düsseldorf, 1961), blz. 175177 , is in de aanhef de volgende passage te lezen:

„..... hebben de eer, uitvoering gevende aan de voorschriften van artikel 108 van de „Wet op de rechtsvorm der naamloze vennootschappen" van 17 juli 1951 , het volgende rapport uit te brengen: ......"

In artikel 109 van de Wet komt verder thans de bepaling voor dat een derde van de aandeelhouders zo nodig hun eigen „censores” kunnen benoemen voor "gewone” en ,bijzondere” onderzoekingen. Hierbij staat overigens niet dat dit „censores jurados de cuentas" moeten zijn.

\section{De functie van de "censor"}

In artikel 3 van de in 1962 gewijzigde statuten van het Instituut der "censores" worden drie functies genoemd die uitsluitend door de „censor jurado de cuentas” vervuld mogen worden:

1 het controleren van jaarrekeningen, toelichtingen enz. van naamloze vennootschappen als hij ingevolge artikel 108 van eerdergenoemde wet geroepen wordt die te controleren;

2 het doen van gewone en bijzondere onderzoekingen bij bedoelde naamloze vennootschappen als het gaat om opdrachten ingevolge artikel 109 van genoemde wet;

3 het controleren van de rekeningen van handelsvennootschappen, en het uitoefenen van andere functies, voorzover zij krachtens wettelijke beschikking worden voorgeschreven door de overheid.

Naast deze factoren geeft ook de bepaling van artikel 108 inzake het verlenen van bijstand door ,personas tecnicas” een stimulans voor de functie van de „censor". Met de bepalingen van artikel 108 heeft de Overheid in 1951 een eerste (schuchtere) poging gedaan om de functie van de „censor jurado de cuentas" in te leiden bij het bedrijfsleven. Toch is deze functie tot heden nog maar zeer beperkt gebleven.

Behalve de genoemde wettelijke prerogatieven zijn er geen werkzaamheden die exclusief aan de "censor" zijn voorbehouden. Bij het verrichten van zijn vele andere werkzaamheden - ook op het gebied der accountancy - ontmoet hij verschillende andere deskundigen, zoals b.v. de "titulares mercantiles" die geen „censor jurado" zijn.

Als men zich in dit verband de vraag stelt waarin in de praktijk het werk van de „,censor jurado" verschilt van dat van de „titular mercantil” die geen „censor jurado" is, moet daarop geantwoord worden dat dit verschil (nog) slechts gering is, behalve dan dat de "censor jurado" via zijn statuten, interne reglement en

3) Zie „Probleme neuzeitlicher Unternehmensführung aus der Sicht der Organisation des Rechnungswesens - Prüfung des Jahresabschlusses - Unternehmensbesteuerung"; Zürich. Blz 195. 
erecode zwaarder gebonden is aan een gewetensvolle uitoefening van het beroep.

Thans volgen hieruit enkele voorbeelden van de wijze waarop getracht wordt een zo goed mogelijke vervulling van de functie te bereiken.

- Eed

De ,censor" moet - om in het bezit te komen van zijn titel - de eed afleggen waarin hij beloof $t$ dat al zijn beroepshandelingen op ieder moment zullen beantwoorden aan "de meest zuivere beginselen van een gezonde moraal en beroepsethiek" (artikel 77 van het Interne Reglement).

\section{Beroepsethiek (algemeen)}

De ethische en morele beginselen en normen, die de „censores" in acht moeten nemen zowel met betrekking tot de beroepshandelingen als in het algemeen, zijn neergelegd in de „Código de Etica Profesional”.

\section{- Beroepsgedrag}

De ,censor" moet de relatie met zijn client persoonlijk onderhouden; hij mag ze niet delegeren aan assistenten, tenzij het werkzaamheden van ondergeschikte aard betreft (artikel 15). De ,censor” moet in zijn verhouding tot de client en ook overigens in al zijn gedragingen ,de hoogste beroeps- en persoonlijke waardigheid" tonen; hij moet integer zijn; vage, misleidende en bedriegelijke oordelen vermijden en zich bij zijn meningsvorming altijd laten leiden door ,objectieve wetenschappelijke en zuivere vaktechnische beginselen" (artikel 17).

\section{- Incompatibiliteiten}

Het administratief werkzaam zijn in dienstbetrekking en het optreden als makelaar en als handels- en verzekeringsagent is absoluut onverenigbaar met het beroep van ,censor”.

Verder zijn er algemene (uit de aard van het beroep voortvloeiende) en specifieke onverenigbaarheden (het fungeren in een bepaald geval).

Voorbeelden van de eerste zijn: procureur bij rechtbanken en andere functies tot de wetgevende of rechterlijke macht behorende. Leden, die dergelijke functies willen vervullen, kunnen niet "censor numerario" (lid in beroep) zijn, maar moeten ,censor supernumerario" (lid - niet in beroep) van het Instituut worden.

Voorbeelden van specifieke onverenigbaarheden zijn dienstverband bij bedrijven die de ,,censor" zou willen controleren en bloedverwantschap tot in de vierde graad met bestuurders van die ondernemingen.

\section{- Beroepsgebeim}

De oordelen van de „censor”, neergelegd in zijn overwegingen, rapporten of verklaringen voor zijn opdrachtgever, dragen en behouden een strikt persoonlijk karakter, behalve indien de rechterlijke macht hem gelast mededelingen daaromtrent te doen (artikelen 33 e.v.).

- Sankties

a Als de ,censor” een fout begaan heeft zonder dat hij een voldoende excuus daarvoor kan aanvoeren of nalatig is geweest, kan hem gedurende een periode van ten hoogste twee jaar worden verboden het beroep uit te oefenen. 
b Als gebleken is dat de „,censor" bepaalde handelingen met een opzettelijk verkeerde bedoeling heeft verricht of fraude heeft gepleegd, wordt hij geroyeerd als lid van het Instituut (artikelen 43 e.v.).

Wat de organisatorische vorm betreft, waarin het beroep van ,censor jurado de cuentas" kan worden uitgeoefend: dit kan als alleenwerkend accountant, maar men kan zich ook associeren. De associaties moeten de goedkeuring van het Instituut hebben.

Als men zich na het voorgaande afvraagt welke de werkelijke situatie van het beroep in Spanje is, moet men zeggen dat er twee redenen zijn welke de ontwikkeling van het beroep aldaar vele jaren hebben tegengehouden:

1 de opleiding was lange tijd van onvoldoende niveau om respect af te dwingen.

De regionale versnippering van de beroepsgenoten en de gevolgen daarvan (zie voor) deden daar ook geen goed aan;

2 het bedrijfsleven had, als geheel genomen, weinig behocfte aan de accountantsfunctie in de ware zin van het woord.

Stelt men zich vervolgens de vraag of er gunstige perspectieven zijn voor de ontwikkeling van het accountantsberoep, dan kan deze vraag toch bevestigend beantwoord worden.

a van de kant van het bedrijfsleven

$\mathrm{Na}$ de burgeroorlog heeft er jarenlang een zeer zw are belastingdruk op het Spaanse bedrijfsleven gelegen met alle gevolgen die deze in het bedrijfsleven opriep. De laatste jaren is de fiscale druk echter op verschillende punten belangrijk verlicht; onder meer: afschaffing van de progressic in de winstbelasting, het recht om $50 \%$ van de overwinst belastingvrij te investeren ter vernieuwing en uitbreiding van het productie-apparaat, het erkennen van het beginsel van de vervangingswaarde (aanvankelijk gold de verplichting van afschrijving op historische kostprijs voor de berekening van de belastbare winst, hetgeen bij de sterke geldontwaarding tot grote vermogensverliezen leidde. Wat de toepassing van het beginsel der vervangingswaarde betreft, is het wachten nog op de vaststelling door de Overheid van de herwaarderingscoefficiënten; deze zullen in principe parallel lopen met het verloop van de geldontwaarding).

Ook uit anderen hoofde staat het bedrijfsleven voor problemen: de vroegere (tot op zekere hoogte) afsluiting van Spanje van de buitenwereld loopt af; de Frotectie door middel van hoge invoerrechten op velerlei gebied zal op de duur wegvallen. Er is bovendien reeds een steeds groter wordende vrijheid voor buitenlandse investeringen.

Door deze beide oorzaken is er een grote behoefte aan advies ontstaan en daarmee een grote vraag naar ,titulares mercantiles" en administratieve deskundigen. De behoefte aan administratie als een "tool for management” en als een verdediging tegenover de fiscus, zal - naar het bestuur van het Instituut der „censores” heeft uiteengezet - een grote vlucht nemen.

b van de kant van het beroep

In de kringen van het Instituut der ,censores” is men zich bewust dat er aan opleiding en practische vorming nog veel te doen is, maar toch is het van veel belang dat het niveau van de opleiding op de handelsscholen en de bedrijfseconomische studie aan de Universiteiten reeds sterk verbeterd zijn. 
Men kan niet zeggen dat er in Spanje gesproken kan worden van een uitoefening van het accountantsberoep zoals dat in Nederland het geval is.

Toch neeme de betekenis van de functie van de „censor jurado de cuentas” langzaam in betekenis toe. Dat dit het geval is, kan men ook afleiden uit het feit dat er de laatste jaren een drang is ontstaan naar een reorganisatic van het Instituut der ,"censores" in die zin, dat dit zijn poorten zou openen voor alle ,profesores mercantiles" die behalve hun titel, kunnen aantonen dat zij de praktijk een bepaald aantal jaren hebben uitgeoefend en een bepaalde hoeveelheid extra kennis bezitten. Deze drang heeft er thans - in 1962 - toe geleid dat het Instituut inderdaad zijn deuren heeft opengezet voor de „profesores mercantiles”. De meesten van hen - 660 in totaal - hebben nu het lidmaatschap aangevraagd. Het bestuur van het Instituut heeft medegedeeld m.b.t. de toelating van deze 660 candidaten een soepele houding te zullen aannemen.

Een heel andere overweging voor deze toelating is dat het Instituut - dat, zoals gezegd, weinig aanvulling krijgt uit de adjunct-leden - op deze wijze een versterking van zijn ledental bereikt. 